Article

\title{
Bioactivities of Geranium wallichianum Leaf Extracts Conjugated with Zinc Oxide Nanoparticles
}

\author{
Banzeer Ahsan Abbasi ${ }^{1, \dagger}{ }^{\text {, Javed Iqbal }}$ 1,*,+® , Riaz Ahmad ${ }^{2}$, Layiq Zia ${ }^{3}$, Sobia Kanwal ${ }^{4}$, \\ Tariq Mahmood ${ }^{1}$, Canran Wang ${ }^{5}$ and Jen-Tsung Chen ${ }^{6, *(\mathbb{C})}$ \\ 1 Department of Plant Sciences, Quaid-i-Azam University, Islamabad 45320, Pakistan; \\ benazirahsanabbasi786@gmail.com (B.A.A.); tmahmood.qau@gmail.com (T.M.) \\ 2 College of Life Sciences, Shaanxi Normal University, Xi'an 710119, China; riaz17qau@gmail.com \\ 3 Superconductivity and Magnetism Laboratory, Department of Physics Quaid-i-Azam University, \\ Islamabad 45320, Pakistan; layiqxia@gmail.com \\ 4 Department of Zoology, University of Gujrat, Sub-Campus Rawalpindi, Punjab 46300, Pakistan; \\ sobiakanwal16@gmail.com \\ 5 Department of Biochemistry and Molecular Cell Biology, Shanghai Key Laboratory for Tumor \\ Microenvironment and Inflammation, Shanghai Jiao Tong University School of Medicine, Shanghai 200025, \\ China; canranw@gmail.com \\ 6 Department of Life Sciences, National University of Kaohsiung, Kaohsiung 811, Taiwan \\ * Correspondence: javed89qau@gmail.com (J.I.); jentsung@nuk.edu.tw (J.-T.C.) \\ + Equally contributed.
}

Received: 26 October 2019; Accepted: 17 December 2019; Published: 26 December 2019

check for updates

\begin{abstract}
This study attempts to obtain and test the bioactivities of leaf extracts from a medicinal plant, Geranium wallichianum (GW), when conjugated with zinc oxide nanoparticles (ZnONPs). The integrity of leaf extract-conjugated ZnONPs (GW-ZnONPs) was confirmed using various techniques, including Ultraviolet-visible spectroscopy, X-Ray Diffraction, Fourier Transform Infrared Spectroscopy, energy-dispersive spectra (EDS), scanning electron microscopy, transmission electron microscopy, and Raman spectroscopy. The size of ZnONPs was approximately $18 \mathrm{~nm}$, which was determined by TEM analysis. Additionally, the energy-dispersive spectra (EDS) revealed that NPs have zinc in its pure form. Bioactivities of GW-ZnONPs including antimicrobial potentials, cytotoxicity, antioxidative capacities, inhibition potentials against $\alpha$-amylase, and protein kinases, as well as biocompatibility were intensively tested and confirmed. Altogether, the results revealed that GW-ZnONPs are non-toxic, biocompatible, and have considerable potential in biological applications.
\end{abstract}

Keywords: Zinc oxide nanoparticles; anticancer; antileishmanial; antimicrobial; biocompatibility

\section{Introduction}

Nanotechnology is one of the important thriving and rapidly developing interdisciplinary sciences involving a combination of knowledge from materials science, physics, chemistry, and biology, etc. The term "nano" is a Greek word which means "extremely small or dwarf" in size range of about one to one-hundred nanometers. NPs possess unique and fascinating magnetic, electrical, optical, and chemical properties with small size, different shapes, and surface effects compared to bulk materials [1-3]. NPs possess breakthrough applications in different fields such as food, agriculture, medicine, cosmetics, energy, environment, and many more [4,5]. Among the different metal nanoparticles (MNPs), zinc oxide nanoparticles (ZnONPs) has received due attention due to their multifunctional and tunable nature. ZnONPs possess $3.37 \mathrm{eV}$ direct band gap with high excitation energy $(60 \mathrm{meV})$, which make it perfect to be utilized in UV photodetector, transistors, and semiconductor diodes [6-8]. In addition, ZnONPs are used in the field of bio-imaging, drug delivery, 
mineral based sunscreens, lotions, and ointments; biomedicine, especially in the fields of anticancer and antibacterial fields, which are involved with their potent ability to trigger excess reactive oxygen species (ROS) production, release zinc ions, and induce cell apoptosis [9].

Numerous physical and chemical routes have been developed to synthesize ZnONPs with disparate morphologies and sizes [10-13]. These physical synthesis routes face numerous problems; they need high energy, costly instruments, and require high temperature and pressure [14]. Meanwhile, chemical approach involves synthesis of ZnONPs using several reducing agents, costly metal salts, toxic solvents, and reductants. These physical and chemical methods are not only expensive at industrial level production, but also possess potential environmental and biological hazards [15-18]. In contrast, biological/biogenic synthesis of NPs is an emerging area and economically feasible option in the field of "green chemistry" [19-22]. It is considered to be simple, safer, greener, easily scaled up, non-toxic, eco-friendly, energy-efficient, cost-effective, and performed at room temperature and pressure in the absence of non-hazardous solvents and reductants [19-21]. Biological fabrication of NPs can be accomplished using different bacteria, algae, diatoms, and medicinal plants [22,23]. The major disadvantage associated with microbial sources is maintaining contamination free environment, high isolation cost and their maintenance in culture media. Therefore, plants (phytofabrication) promise to be an excellent route in the formation of NPs due to simplicity, replacing chemicals to lessen or even remove materials that are harmful to human health and the ecosystem [24]. The use of a plant-extract in the synthesis of NPs has recently gained significant popularity $[20,25]$. The phytochemicals available in plants act as a reducing agents, leading to a synthesis of capped NPs, and thus reducing costs and chemical reagents $[25,26]$. Further, phytochemicals and aqueous environment replace many harmful organic/inorganic solvents and chemical compounds [26]. Currently, plant extracts of various plant parts have been used in the biofabrication of NPs [25]. Plant extracts possess potential biological activities in biomedical applications due to the presence of different phytomolecules: alkaloid, flavonoid, phenolic, terpenes, amino acids, and vitamins may function as strong reducing and stabilizing agents, reducing cost and eliminating the use of toxic chemicals agents [27-30].

Numerous investigations have focused on the green synthesis of ZnONPs and have reported different biological activities [31-34]. Considering the importance of green synthesis, in the present study, ZnONPs have been synthesized using GW leaves extract. The plant possesses many therapeutic application in the treatment of rheumatism, leucorrhoeas, arthritis, gonorrhea, heart, and liver related problems. Among the various plants used in the formation of green NPs, GW was selected due to large amount of bioactive compounds; ursolic acid, herniarin, stigmasterol, $\beta$-sitosterol, herniarin, etc. which can help in the reduction, stabilization, and capping of metal ions [35].

The aim of the current research study was to biosynthesize ZnONPs (Zinc nitrate hexahydrate) using natural GW leaves extract without utilizing any surfactants and chemical solvents. The reaction condition and synthesis protocol have been discussed comprehensively. To the best of our knowledge, this is the first research study reporting green fabrication of ZnONPs using GW leaves extract. Furthermore, ZnONPs were extensively studied using various characterizations techniques, followed by investigations of its diverse bio-potentials using number of activities and assays.

\section{Experimental}

\subsection{Plant Sampling and Extract Preparation}

Geranium wallichianum (Geraniaceae) was collected in its flowering stage from Nathiagali Mountains ( $\left.34^{\circ} 04^{\prime} \mathrm{N} 73^{\circ} 23^{\prime} \mathrm{E}\right)$, Khyber Pakhtunkhwa, Pakistan. The soil is typically moist, loamy, and very shallow. The weather remains cool, pleasant and foggy in summers, cold and chilly in winters with heavy snow [35]. The leaves of GW were thoroughly washed with deionized water, shade dried for 10-15 days so that water content gets removed entirely. The leaves were crushed to powder and preserved in dry and airtight container. The plant extract was prepared by mixing $10 \mathrm{~g}$ of GW fresh leaves powder with $250 \mathrm{~mL}$ distilled water. The mixture was heated for $2 \mathrm{~h}$ at $80{ }^{\circ} \mathrm{C}$ under continuous 
stirring. The resulting solution was cool down at room temperature and filtered three times utilizing Whatman filter papers. The resulting filtered extract was preserved at $4{ }^{\circ} \mathrm{C}$ for future use in the biofabrication of ZnONPs.

\subsection{Synthesis of $\mathrm{ZnONPS}$}

Synthesis of $\mathrm{ZnONPs}$ was successfully performed by reducing $\mathrm{Zn}\left(\mathrm{NO}_{3}\right)_{2} \cdot 6 \mathrm{H}_{2} \mathrm{O}$ using GW leaf extract. In detail, $50 \mathrm{~mL}$ filtered GW leaves extract was taken and mixed with $3 \mathrm{gm} \mathrm{Zn}\left(\mathrm{NO}_{3}\right)_{2} \cdot 6 \mathrm{H}_{2} \mathrm{O}$ salt, heated at $60{ }^{\circ} \mathrm{C}$, and continuously stirred at $500 \mathrm{rpm}$ for $2 \mathrm{~h}$. The obtained solution was centrifuged at 12,000 rpm/30 min. The pellet containing ZnONPs was carefully washed 3-4 times with double distilled water. The obtained powder assumed as ZnONPs was placed in an oven at $\sim 100{ }^{\circ} \mathrm{C}$ for $3 \mathrm{~h}$. Further, ZnONPs were calcined in a furnace to obtain crystalline ZnONPs. The calcined ZnONPs were kept in a cool, dry, and dark place, and their characterizations were performed. Figure 1 shows a study layout of $\mathrm{ZnONPs}$ from synthesis to characterization and biological applications.

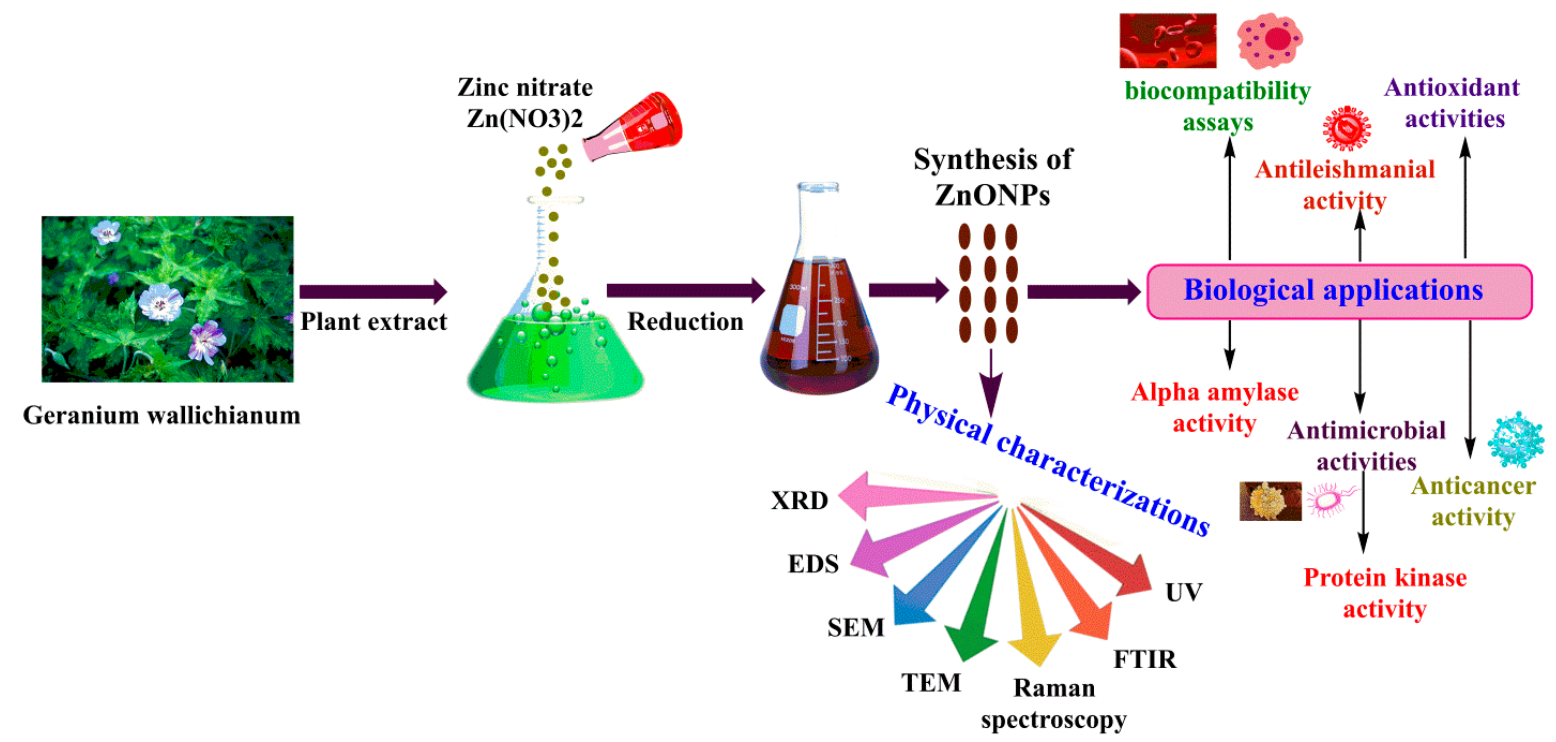

Figure 1. The process of green synthesis of leaf extract-conjugated zinc oxide nanoparticles.

\subsection{Characterization of $\mathrm{ZnONPS}$}

The biogenic ZnONPs were characterized morphologically, physically, and chemically using various analytical techniques. The bio reduction of zinc ions to ZnONPs was determined by measuring the absorption spectra of reaction solutions via UV-4000 UV-Vis spectrophotometer (Germany) between 200-700 nm. The morphology of the ZnONPs was analyzed through SEM (EM (NOVA FEISEM-450 applied with EDX detectors). TEM analyses was performed to study size and shape of ZnONPs. The average particle size and particle size distribution of ZnONPs were studied via DLS system, using Malvern Zetasizer Nano (Malvern instrument). FTIR (Alpha, Bruker, Germany) analysis was performed between $500-4500 \mathrm{~cm}^{-1}$ to study diverse types of functional groups which are responsible in reduction and effective stabilizations for ZnONPs using various modes of vibrations. The crystalline structure of biogenic ZnONPs was determined by PANalytical XRD (Netherland) and crystal size was calculated. The Raman spectroscopy analyses was performed for ZnONPs to study their vibrational properties. The EDS analyses were done to detect the elemental composition of ZnONPs.

\subsection{Bio-Potentials of Green GW-ZnONPs}

\subsubsection{Metabolic Activity of GW-ZnONPs against HepG2 Cells}

The MTT cytotoxicity assay was performed according to the previously described method to assess the survival (viability) of the HepG2 (liver cancer cells) by assessing the mitochondrial activity 
inside the cells after treatment with ZnONPs. For this purpose, HepG2 cells were cultured in DMEM media provided with 10\% FBS, $1 \%$ Pen-Strep. Cells were seeded in 96-well plates and placed in 5\% $\mathrm{CO}_{2}$ incubator at $37^{\circ} \mathrm{C}$ for cell attachment. To assess the cytotoxicity potentials of green ZnONPs, HepG2 cells were treated with different doses of zinc oxide nanoparticles $(7.8125-1000 \mu \mathrm{g} / \mathrm{mL})$ for $48 \mathrm{~h}$ and MTT assay was performed. The ZnONPs treated cells were placed in DMEM medium and placed in an incubator for $24 \mathrm{~h}$. After incubation, $100 \mu \mathrm{L}$ MTT solutions was loaded and set aside for $\sim 2 \mathrm{~h}$. The MTT dye reacted with the oxidoreductase enzyme present in the mitochondria and was then converted into crystals of formazan. This process occurred only in viable cells. Further, the formazan crystals were dissolved with dimethyl sulfoxide (DMSO) and its absorbance was measured using a plate reader at $570 \mathrm{~nm}$. Untreated cells were considered as control, while \% inhibition of HepG2 cell lines treated with the synthesized ZnONPs nanoparticles was calculated using the formula below.

$$
\% \text { inhibition }=\frac{1-\text { OD of sample }}{\text { OD of control }} \times 100
$$

\subsubsection{Antileishmanial Potential of $\mathrm{ZnONPs}$}

The cytotoxicity potentials of ZnONPs were further evaluated using Leishmania tropica "KWH23 strain" (both amastigotes and promastigotes culture) utilizing cytotoxicity assay [30,36]. The MI99 media was used added with 10\% FBS to culture leishmanial parasites. The leishmanial parasites were treated with various concentrations of ZnONPs $(1-200 \mu \mathrm{g} / \mathrm{mL})$ to evaluate their antileishmanial potentials. During the experiment, Amphotericin-B was considered positive and DMSO as negative control. The Leishmanial parasites in 96 well plates were treated with various concentrations of $\mathrm{ZnONPs}$ and kept in $5 \% \mathrm{CO}_{2}$ incubator for $72 \mathrm{~h}$ at $24{ }^{\circ} \mathrm{C}$, and absorbance was measured at $540 \mathrm{~nm}$. After treatment, all living leishmanial parasites were counted under a microscope and $\mathrm{IC}_{50}$ values were recorded. Median lethal concentration $\left(\mathrm{IC}_{50}\right)$ was calculated using GraphPad software, while percent inhibition was calculated using the following formula:

$$
\% \text { inhibition }=\frac{1-\text { sample absorbance }}{\text { absorbance of control }} \times 100
$$

\subsubsection{Alpha Amylase (AA) Inhibition Potential}

The AA inhibition potential of biogenic ZnONPs was determined using a previously described method [36]. The reaction mixture for the activity was made by mixing $25 \mu \mathrm{L}$ of AA enzyme, $10 \mu \mathrm{L}$ ZnONPs, $40 \mu \mathrm{L}$ starch solutions, and $15 \mu \mathrm{L}$ FBS. The reaction solution with all component was incubated at $50{ }^{\circ} \mathrm{C}$ for $30 \mathrm{~min}$ by adding $1 \mathrm{M} \mathrm{HCL}(20 \mu \mathrm{L})$ and iodine solutions $(90 \mu \mathrm{L})$. The acarbose was utilized as positive and distilled water was utilized as negative control during experiment. Median lethal concentration $\left(\mathrm{IC}_{50}\right)$ was calculated using GraphPad software while percent inhibition was calculated using the following formula:

$$
\% \text { inhibition }=\frac{\text { sample absorbance }- \text { absorbance of negative control }}{\text { absorbance of blank }- \text { absorbance of negative control }} \times 100
$$

\subsubsection{Protein Kinase (PK) Inhibition Potential}

The ZnONPs were also evaluated for its PK inhibition potential using Streptomyces 85E strain according to a previously published method [37]. The PK inhibition activity was conducted in a sterile environment. The SP4 minimal media was utilized to prepare even lawns of Streptomyces. $10 \mu \mathrm{L}$ of ZnONPs loaded on filter discs were placed on the petri plates to determine their PK inhibition potential. The surfactin was taken as positive and DMSO as negative control. To target the growth of Streptomyces $85 \mathrm{E}$ strain, incubation was performed at $30^{\circ} \mathrm{C}$ for $72 \mathrm{~h}$. After $24 \mathrm{~h}$, clear and bald zones appeared around the discs, which showed spores inhibition and mycelia development. Finally, zone of inhibition (ZOI) were measured. 


\subsubsection{Antifungal Assays of $\mathrm{ZnONPs}$}

Fungicidal potentials of biogenic ZnONPs were investigated against different fungal strains via disc diffusion method. Before fungicidal assay was performed, fungal spores were sub-cultured in Sabouraud Dextrose liquid media and kept in an incubator for $24 \mathrm{~h}$ at $37^{\circ} \mathrm{C}$. The liquid cultures of different fungal strains were adjusted to OD of 0.5. Further, SDA solid media was made for culturing fungal strains and poured into petri plates. Filter discs laden with different concentrations of ZnONPs were kept on media plates. The Amphotericin-B was taken as positive and DMSO as negative controls. After loading test samples and both positive and negative controls, fungal plates were kept in an incubator for $\sim 48 \mathrm{~h}$ at $28^{\circ} \mathrm{C}$ to observe the $\mathrm{ZOI}$. The fungal strains were treated with various concentrations of ZnONPs ranging from 31.25-1000 $\mu \mathrm{g} / \mathrm{mL}$, and their MIC value was recorded to determine their antifungal potential.

\subsubsection{Antibacterial Activity of $\mathrm{ZnONPs}$}

The bacterial inhibition potential of GW-ZnONPs were evaluated using various bacterial strains through discs-diffusion method. Before the activity was conducted, bacterial strains were sub-cultured overnight in nutrients broth media and incubated at $37^{\circ} \mathrm{C}$ for $24 \mathrm{~h}$. To determine the antibacterial potency of ZnONPs, an overnight culture of bacterial strains was spread on pre-prepared agar media and allowed to dry for $5 \mathrm{~min}$. Subsequently, filter discs laden with different concentration of ZnONPs (31.25-1000 $\mu \mathrm{g} / \mathrm{mL})$ were dried and kept on surface of plates. The plates were kept in incubator at $37^{\circ} \mathrm{C}$ for $24 \mathrm{~h}$ and observed for ZOI. The standard antibiotic oxytetracycline was taken as positive and $5 \%$ DMSO as negative control. Further, MIC values of GW-ZnONPs were determined by calculating ZOI.

\subsubsection{Antioxidant Capacities}

The radical scavenging potential of ZnONPs was determined using spectrophotometric procedure. The working solution was prepared by mixing DPPH $(2.4 \mathrm{mg})$ into $25 \mathrm{~mL}$ of methanol as free radicals. Before the activity was started, various concentrations (1-200 $\mu \mathrm{g} / \mathrm{mL})$ of ZnONPs were prepared and evaluated for their antioxidant potential. The ascorbic acid (AA) was taken as positive and DMSO as negative control. The $200 \mu \mathrm{L}$ of reaction mixtures was comprised of $180 \mu \mathrm{L}$ of reagent solution and $20 \mu \mathrm{L}$ ZnONPs sample. The reaction mixture was then kept for $2 \mathrm{~h}$ under dark conditions and absorbance of reaction mixture was measured at $517 \mathrm{~nm}$. The scavenging potential of GW-ZnONPs on free radicals are presented as follows:

$$
\% \text { DPPH scavenging }=1-\left(\frac{\text { Absorbance of sample }}{\text { Absorbance of control }}\right) \times 100
$$

The antioxidant potential of ZnONPs was further studied by total antioxidant capacity (TAC) using previously described phosphomollybdenum method [38]. The absorbance was recorded at $695 \mathrm{~nm}$ and results were indicated as microgram equivalent of AA per/mg of test samples. AA was used as positive control and DMSO as negative control. Furthermore, total reducing power (TRP) of the asynthesized ZnONPs were studied using Potassium-ferricyanide procedure [39]. AA was taken as positive and DMSO was taken as negative controls. The absorbance of mixture solutions was recorded at $630 \mathrm{~nm}$. The reducing power of asynthesized ZnONPs was measured as AA equivalents per milligrams (AAE/mg).

\subsubsection{Biocompatibility of ZnONPs with Human Macrophages}

The biocompatible nature of green ZnONPs were investigated using human macrophages via previously used method [40]. The macrophages were cultured in RPMI media supplemented with FBS $(10 \%)$, Herpes $(25 \mathrm{mM})$, antibiotics (Pen-Strep. Further, macrophages were seeded and cultured in 96-well plates, kept in 5\% $\mathrm{CO}_{2}$ incubator for $24 \mathrm{~h}$ for cell attachment. The macrophages were exposed 
to various concentrations of biogenic ZnONPs $(1-200 \mu \mathrm{g} / \mathrm{mL})$ for $24 \mathrm{~h}$. The absorbance was measured and $\%$ inhibition was calculated using the equation below.

$$
\% \text { inhibition }=\frac{1-\text { Absorbance of sample }}{\text { Absorbance of control }} \times 100
$$

\subsubsection{Biocompatibility of ZnONPs with Human RBCs}

The biocompatible nature of asynthesized ZnONPs was further confirmed using human RBCs through previously described method [41]. For hemolytic assay, $1 \mathrm{~mL}$ of fresh human RBCs was taken and stored in EDTA falcon to avoid blood coagulation. Further, centrifugation was performed for human RBCs at 12,000 rpm for $10 \mathrm{~min}$. The erythrocytes suspension was made by adding $200 \mu \mathrm{L}$ erythrocytes into $9.8 \mathrm{~mL}$ of PBS ( $\mathrm{pH} 7.2$ ). The $100 \mu \mathrm{L}$ erythrocytes suspensions was treated with various doses of $\mathrm{ZnONPs}$ and incubated at $35^{\circ} \mathrm{C}$ for $1 \mathrm{~h}$. Further, centrifugation was performed at $12,000 \mathrm{rpm}$ and supernatants was removed. Further, the supernatant was shifted into 96-well-plate and hemoglobin release was studied at $540 \mathrm{~nm}$. During experiment, Triton X-100 was utilized as positive and DMSO as negative control. The results are calculated as \% hemolysis produced by different concentration of ZnONPs and can be calculated employing the formula below:

$$
\% \text { hemolysis }=\frac{\text { Sample abs }- \text { Negative control abs }}{\text { Positive control abs }- \text { Negative control abs }} \times 100
$$

\section{Results and Discussion}

\subsection{Biosynthesis of ZnONPs}

In this present study, ZnONPs were rapidly fabricated using GW leaves extract as a bioreductant and stabilizing agents. Different characterization techniques were performed to determine the formation of zinc oxide nanoparticles. The progress of synthesis of ZnONPs was detected by color change after the addition of precursor salt to plant extract at $60{ }^{\circ} \mathrm{C}$. The color change in solutions (reddish black) signal the biosynthesis of ZnONPs. This color change in the solution is due to surface plasmon resonance (SPR) [42]. To confirm the stable nature of asynthesized ZnONPs, $1 \mathrm{mg} / \mathrm{mL}$ solutions of nanoparticles was prepared and sonicated for $\sim 40 \mathrm{~min}$. The turbid colloidal suspension was allowed to remain stable for $48 \mathrm{~h}$, and SPR was observed with varied time interval. The wavelength scale was fixed between 200-700 nm and solution was scanned between this range. The UV spectra showed absorption peak at $398 \mathrm{~nm}$, indicating that colloidal suspension remained stable for $48 \mathrm{~h}$. The reduction in absorption peak was noticed after $60 \mathrm{~h}$ which showed settlement of NPs at the bottom. The UV-Vis spectrum for green ZnONPs are presented in Figure 2A,B. The XRD configurations of thermally annealed green GW-ZnONPs are presented in Figure 2C. The XRD analysis has confirmed the crystalline nature of $\mathrm{ZnONPs.} \mathrm{The} \mathrm{resulting} \mathrm{Bragg} \mathrm{peaks} \mathrm{were} \mathrm{in} \mathrm{accordance} \mathrm{with} \mathrm{single} \mathrm{and} \mathrm{pure} \mathrm{phase} \mathrm{hexagonal}$ zincite with JCPD card no: 00-036-1451. The XRD spectra showed different distinct diffraction peak with $2 \varnothing$ value of $32.44,35.13,37.34,47.21,57.51,62.58,65.76$ and 67.61 , which are corresponding to (100), (002), (101), (102), (110), (103), (112) and (201) Bragg's reflections. XRD spectrum obtained indicates the absence of impurities. The presence of these peaks are due to leaves extract containing organic compounds, thus play significant role in reduction of zinc ions and stabilization of resultant ZnONPs [42]. The average size calculated as $\sim 18 \mathrm{~nm}$. The XRD configuration for ZnONPs are consistent with earlier studies using green synthesis protocol $[43,44]$. 


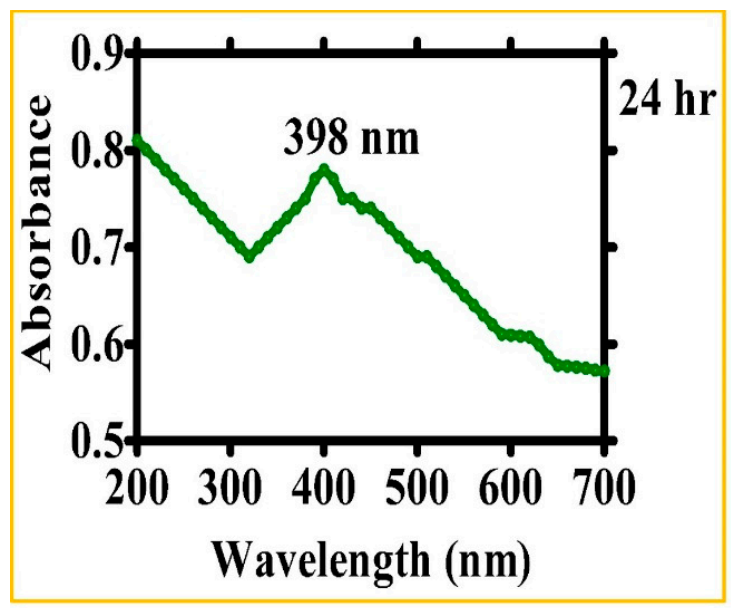

(A)

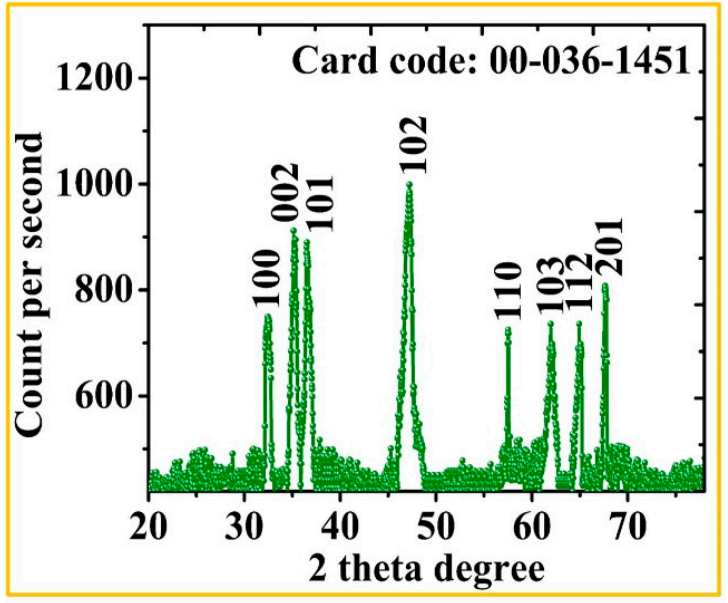

(C)

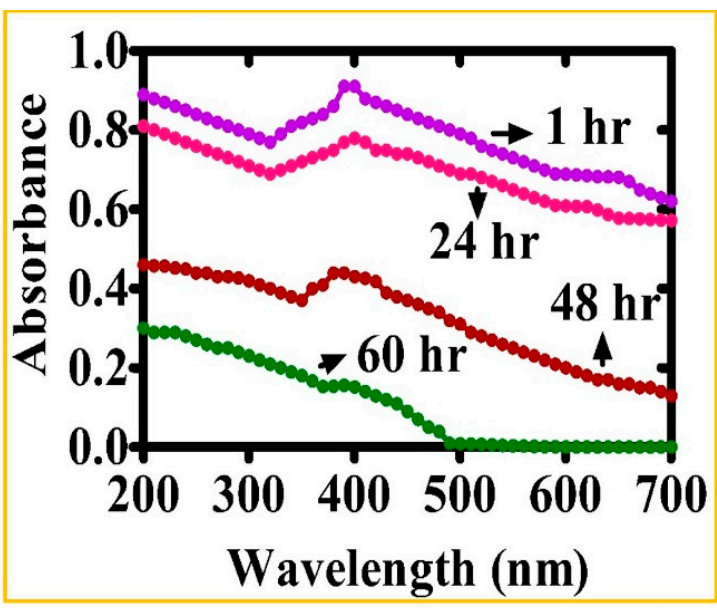

(B)

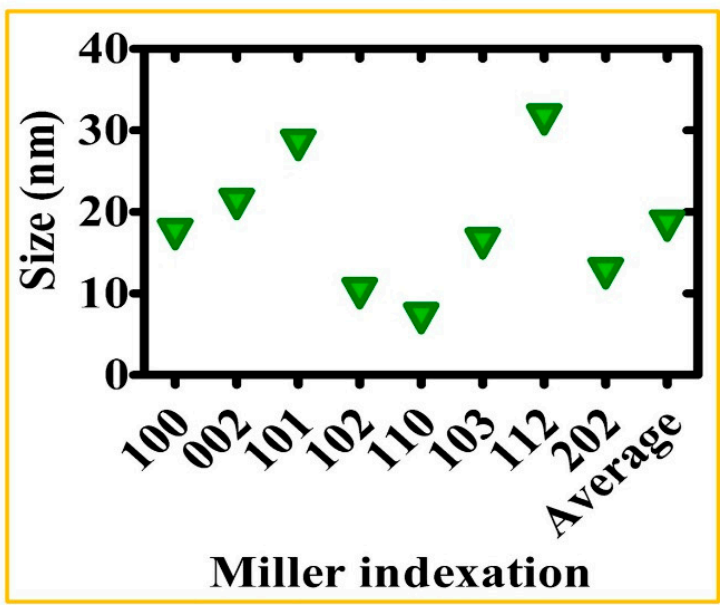

(D)

Figure 2. UV and XRD spectra analysis for biogenic ZnONPs (A) UV visible spectra (B) Stability of biosynthesized ZnONPs (C) XRD spectra of Geranium wallichianum mediated ZnONPs (D) Size calculation via Scherer approximation.

The Raman and FTIR analyses were performed to determine the vibrational properties of ZnONPs. The distinct major modes of Raman spectra are located at $92.5 \mathrm{~cm}^{-1}\left(\mathrm{E}_{2} \mathrm{~L}\right), 180.77 \mathrm{~cm}^{-1}$ (2TAM), $313.23 \mathrm{~cm}^{-1}$ (2E2M), $403.04 \mathrm{~cm}^{-1}$ (E1TO), $565.12 \mathrm{~cm}^{-1}$ (E2H + E2L). Our results of Raman spectra of GW mediated ZnONPs are in agreement with previous studies using $S$. thea [44]. The Raman spectroscopy results are shown in Figure 3A. FTIR analysis was done to recognize the major functional group and their possible role in synthesis and stabilization of ZnONPs. The spectrum of leaves extract mediated zinc oxide nanoparticles is presented in Figure 3B. The peak centered at $3273.31 \mathrm{~cm}^{-1}, 1395.87 \mathrm{~cm}^{-1}$, $1262.46 \mathrm{~cm}^{-1}, 1060.47 \mathrm{~cm}^{-1}$ indicate $\mathrm{O}-\mathrm{H}, \mathrm{C}-\mathrm{C},-\mathrm{CH}$ and $\mathrm{C}=\mathrm{C}$ stretching. The other peaks located at $1565.48 \mathrm{~cm}^{-1}$ correspond to $\mathrm{C}-\mathrm{C}$. Peaks at $530 \mathrm{~cm}^{-1}$ signify $\mathrm{Zn}-\mathrm{O}$ bond vibrations from $\mathrm{ZnONPs}$. There was a shift in the peaks of biogenic ZnONPs which suggests that different functional groups of GW leaf extract are involved in synthesis of ZnONPs and prevent agglomeration [45]. The surface morphology of the biogenic ZnONPs was explored using SEM. The SEM images of biogenic ZnONPs are shown in Figure 4A-C. The smaller the size of nanoparticles, the larger the surface area and stronger the activity will be. Thus, ZnONPs have shown significant biological applications. Further, an insight into the morphology and size detail of ZnONPs was revealed by TEM. TEM image in (Figure 4D) shows that ZnONPs are hexagonal in shape with average size of $\sim 18 \mathrm{~nm}$ which are consistent with 
calculation from XRD. Smaller size NPs with larger surface area have shown numerous applications especially in the field of medicine, chemo, and electrochemistry $[46,47]$. EDX spectra analysis revealed the surface chemical composition of biogenic ZnONPs. The EDX results have shown that all the ionic zinc was resulted into synthesis of ZnONPs leaving no ionic zinc peak. The EDX peaks showed that both $\mathrm{Zn}$ and oxygen exist in test samples while no other elements were observed in the EDX spectrum. The absence of other elements confirms the purity of biosynthesized ZnONPs. The EDX spectrum is shown in Figure 5A. The EDX pattern clearly shows that reduction of Zn salt with GW leaves extract yielding in crystalline ZnONPs. The size distributions, PDI and $\zeta$-potentials (ZP) of thermally annealed ZnONPs were detected by DLS analyses. The results indicated larger particles aggregate of $98.26 \mathrm{~nm}$. The $\mathrm{ZP}$ and PDI of ZnONPs were $-8.53 \mathrm{mV}$ and 0.232 (Figure 5B,C). The details about zeta size and $\mathrm{ZP}$ are given in Table 1. Our DLS results are similar to the previous report of ZnONPs using Ixora coccinea [48]. DLS is performed to confirm the size of NPs in colloid suspension in the range of nano and submicron, and its ZP measurement is based on particles movement under electric field.

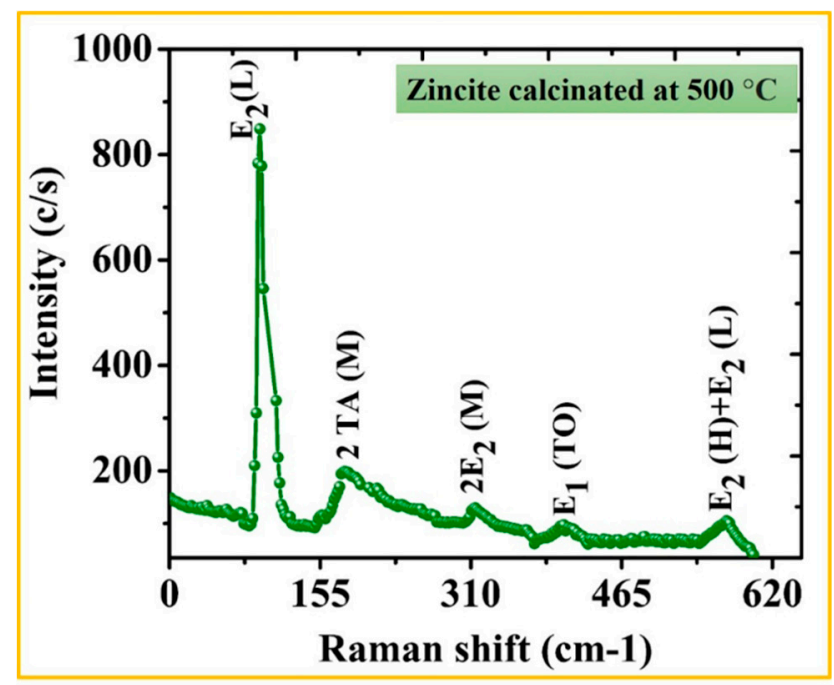

(A)

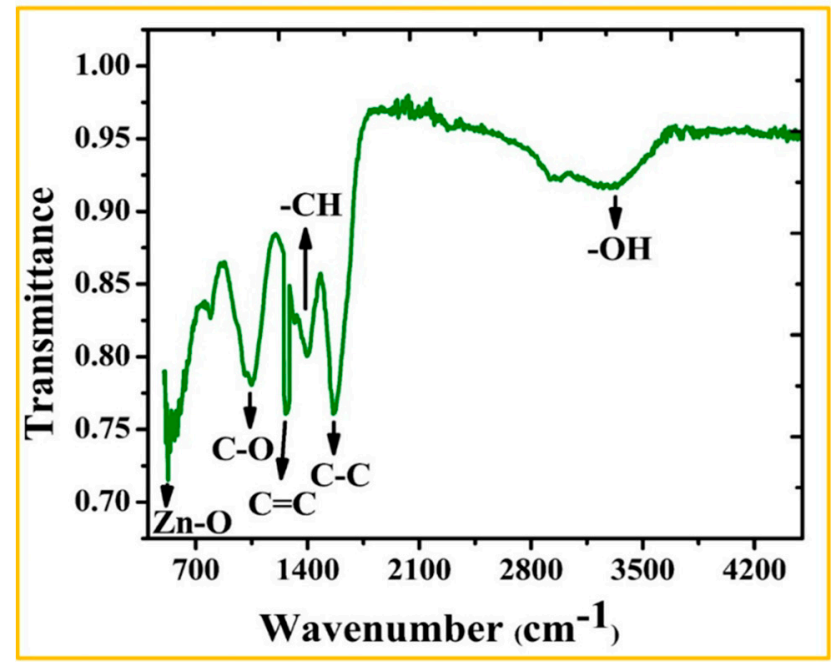

(B)

Figure 3. (A) Raman spectra of the ZnONPs biosynthesized using zinc nitrate hexahydrate as precursor (B) FTIR spectra of ZnONPs. 

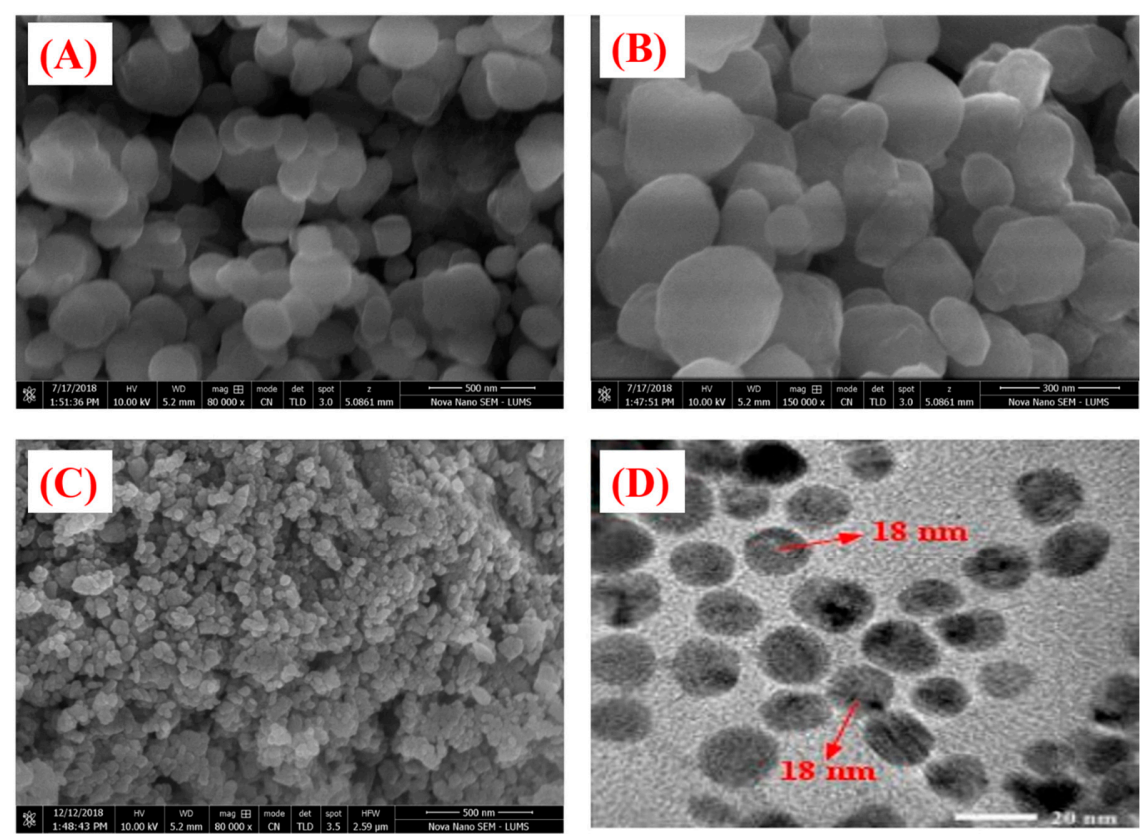

Figure 4. SEM and TEM images of Geranium wallichianum mediated ZnONPs using zinc nitrate as a precursor (A-C) HR-SEM images (D) TEM image.

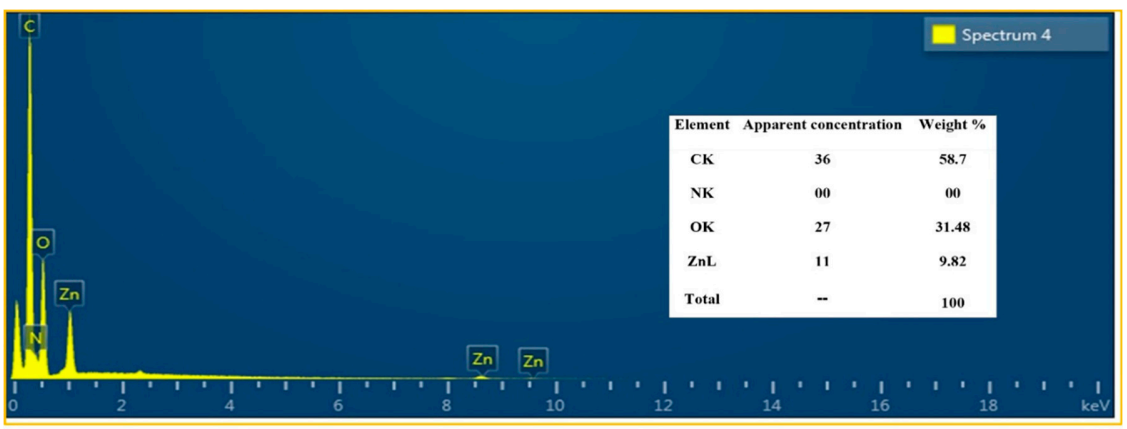

(A)

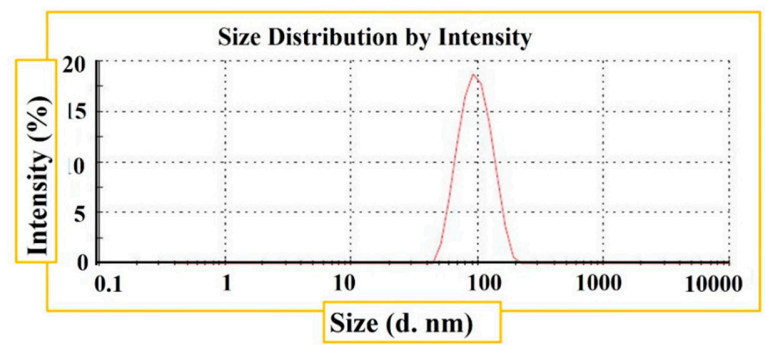

(B)

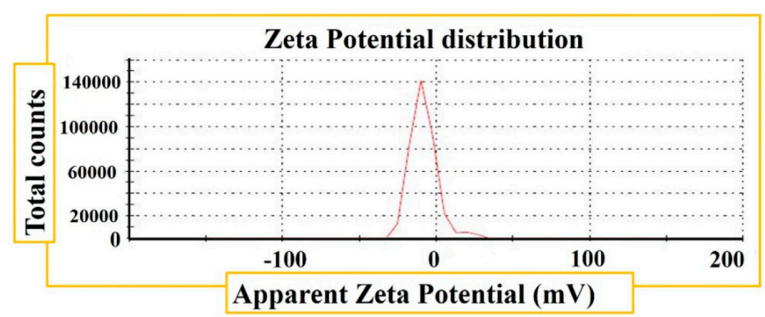

(C)

Figure 5. (A) Elemental composition using EDX (B) Size distribution of Geranium wallichianum mediated ZnONPs (C) Zeta potential measurement of ZnONPs. 
Table 1. Zeta potential measurements of the ZnONPs.

\begin{tabular}{cc}
\hline Zeta Size (d. $\mathbf{n m})$ and Potential $(\mathrm{mV})$ \\
\hline Zeta size & $98.26(\mathrm{~d} . \mathrm{nm})$ \\
Z-Average & $98.09(\mathrm{~d} . \mathrm{nm})$ \\
PdI & 0.232 \\
Intercept & 0.943 \\
Zeta potential & $-8.53 \mathrm{mV}$ \\
Zeta deviation & $9.16 \mathrm{mV}$ \\
Conductivity & $0.00275 \mathrm{mS} / \mathrm{cm}$ \\
Result quality & Good \\
\hline
\end{tabular}

\subsection{Bio-Potentials of Biogenic GW-ZnONPs}

\subsubsection{Metabolic Activity of GW-ZnONPs against HepG2 Cells}

Cancer is a fatal disease, a major cause of deaths around the globe, and is continuously increasing in cause of death by an estimated 21 million by the year 2030 [30,49,50]. Among the numerous types of cancers, liver cancer is presently the second deadliest cancer in males and sixth in female causes $(\sim 745,517)$ deaths. The different risk factors related are viral infection, extensive alcohol use, and toxin exposures (aflatoxin) [51]. The cytotoxicity potential of the synthesized zinc oxide nanoparticles against liver cancer cells (HepG2) was evaluated using MTT cytotoxicity assay. The key results obtained by MTT cytotoxicity assay in HepG2 cells treated with various doses of ZnONPs ranging from $7.8125-1000 \mu \mathrm{g} / \mathrm{mL}$ for $48 \mathrm{~h}$ are summarized in Figure 6A. Our results of ZnONPs have determined strong reduction in the metabolic activity of HepG2 cancer cells. The metabolic activity was reducing continuously with increase in ZnONPs concentrations. The highest inhibition potential ( $\sim 71 \%$ mortality) was achieved at $1000 \mu \mathrm{g} / \mathrm{mL}$ and cytotoxicity potency was decreasing with a decrease in concentration. The reduction in metabolic activity has shown that ZnONPs might have potential anticancer activity. The $\mathrm{IC}_{50}$ value recorded for GW mediated ZnONPs against HepG2 cell lines was $39.26 \mu \mathrm{g} / \mathrm{mL}$. The cytotoxic effects induced by GW-NPs at lower concentrations could be due to the plant components attached to the ZnONPs. The results obtained from this study are also very well supported with various evidences for the cytotoxic effect of green ZnONPs using Rhamnus virgata leaf extract against the liver cancer HepG2 cell line in vitro [52,53].

\subsubsection{Antileishmanial Potential of ZnONPs}

Leishmania is a tropical disease with an excessive epidemiological diversity caused by at least 20 Leishmania species and is transferred by the bite of female sandflies [54]. Leishmanial parasites have wide distribution range in $~ 100$ countries around the world. The drugs present in commercial market for the treatment of leishmaniasis are generally toxic, less potent and expensive. As for example, Antimonials designed as a potential candidate for leishmaniasis therapy has lost its potential against Leishmanial parasites and has developed resistance against it. Thus, pharmaceutical industries are working hard in this direction to develop novel drugs which will be more effective, less toxic, and cost effective for the treatment. Significant research studies have been performed to design MNPs for the treatment of Leishmania. Various NPs have been used in diverse studies to determine cytotoxic potentials against $L$. parasites [34]. However, the biosynthesized ZnONPs are poorly studied for the treatment of L. tropica.

In the present report, antileishmanial potentials of ZnONPs was evaluated using L. tropica (KMH23) Figure 6B. The L. tropica parasites were exposed to various doses $(1-200 \mu \mathrm{g} / \mathrm{mL})$ of $\mathrm{ZnONPs}$ for $72 \mathrm{~h}$. The antileishmanial potentials of $\mathrm{ZnONPs}$ were increasing with an increase in concentrations of ZnONPs and determined significant antileishmanial potentials against $L$. tropica promastigotes with $\mathrm{IC}_{50}: 15.60 \mu \mathrm{g} / \mathrm{mL}$. Similarly, ZnONPs also shown significant potential against $L$. tropica amastigotes with $\mathrm{IC}_{50}: 34.5 \mu \mathrm{g} / \mathrm{mL}$ which are consistent with earlier studies of biosynthesized ZnONPs [34,53]. 
The dose-dependent nature and low $\mathrm{IC}_{50}$ value signify that these $\mathrm{ZnONPs}$ can be utilized in drug delivery for the treatment of leishmaniasis.

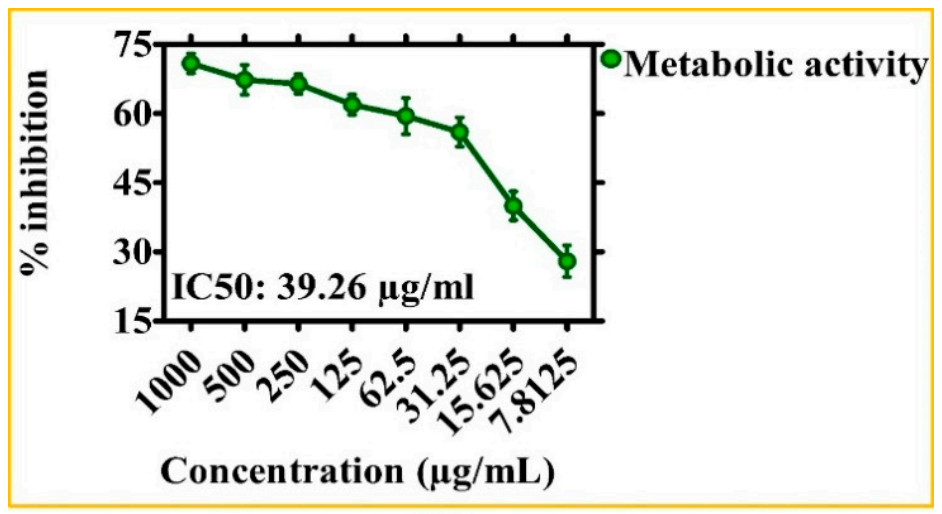

(A)

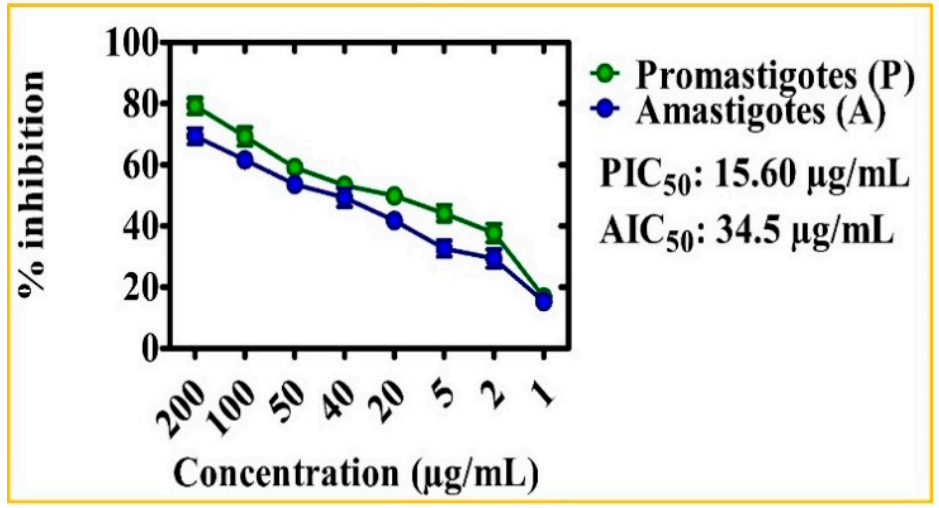

(B)

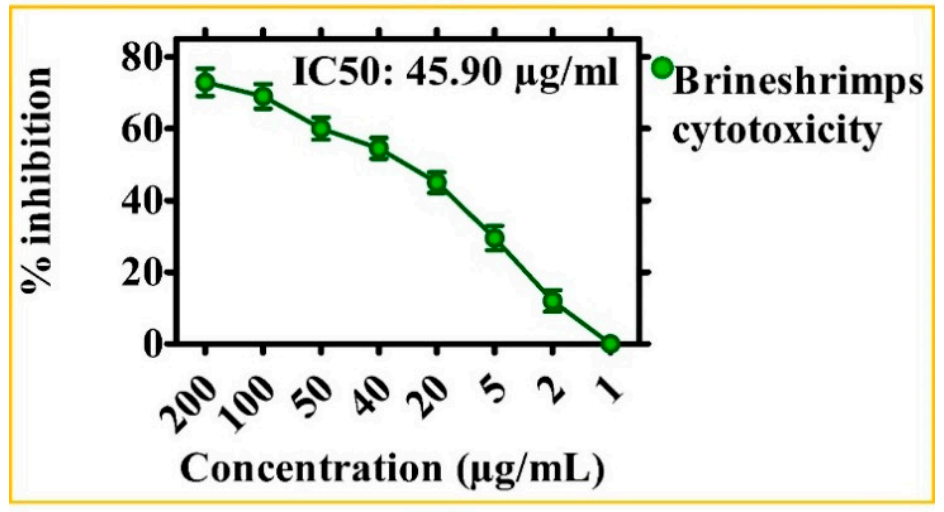

(C)

Figure 6. Cytotoxicity assays. The data in all figures represents the mean of three replicates (A) Cytotoxicity activities of Geranium wallichianum mediated ZnONPs against HepG2 cell line (B) Antileishmanial activities of ZnONPs (C) Cytotoxicity against brine shrimps.

\subsubsection{Antibacterial and Antifungal Activities}

The biogenic zinc oxide nanoparticles have also shown significant antibacterial potential against various bacterial strains (BS). For this purpose, different bacterial strains were treated with various doses of ZnONPs ranging from 31.25-1000 $\mathrm{gg} / \mathrm{mL}$ Figure 7A. The activity was done against different gram positive (S. aureus and B. subtilis) and gram negative BS (P. aeruginosa, K. pneumoniae, E. coli). Most BS were found susceptible where ZnONPs have shown potential results by inhibiting them. $B$. subtilis was reported to be the most susceptible strain with MIC score of $7.8 \mu \mathrm{g} / \mathrm{mL}$ while K. pneumoniae 
was found to be the least susceptible strain with an MIC value of $125 \mu \mathrm{g} / \mathrm{mL}$. Oxytetracycline was taken as positive control while treating BS to different doses of ZnONPs. No single dose has shown stronger potential than positive control. Overall, our ZnONPs have shown potential antibacterial activities against different BS which are in line with the previous reports of biosynthesized nanoparticles [28,55]. The increased antibacterial potential of ZnONPs is due to the bioactive functional groups attached on the surface of NPs. In a nutshell, ZnONPs concluded concentration dependent response against different strains of bacteria. Some other studies have discussed the antibacterial potentials of ZnONPs and shown that ROS generation is the core mechanisms that give antimicrobial potentials to NPs. Further, membrane damage (membrane protein damage) due to NPs absorption on surface result in bacterial cell damaging. Similarly, surface defect in the symmetry of NPs is responsible for bacteria inhibition and causes injury to cells [56]. Besides, different functional groups attached from GW leaves extract result in capped ZnONPs, which play an important role in the bacterial inhibition.

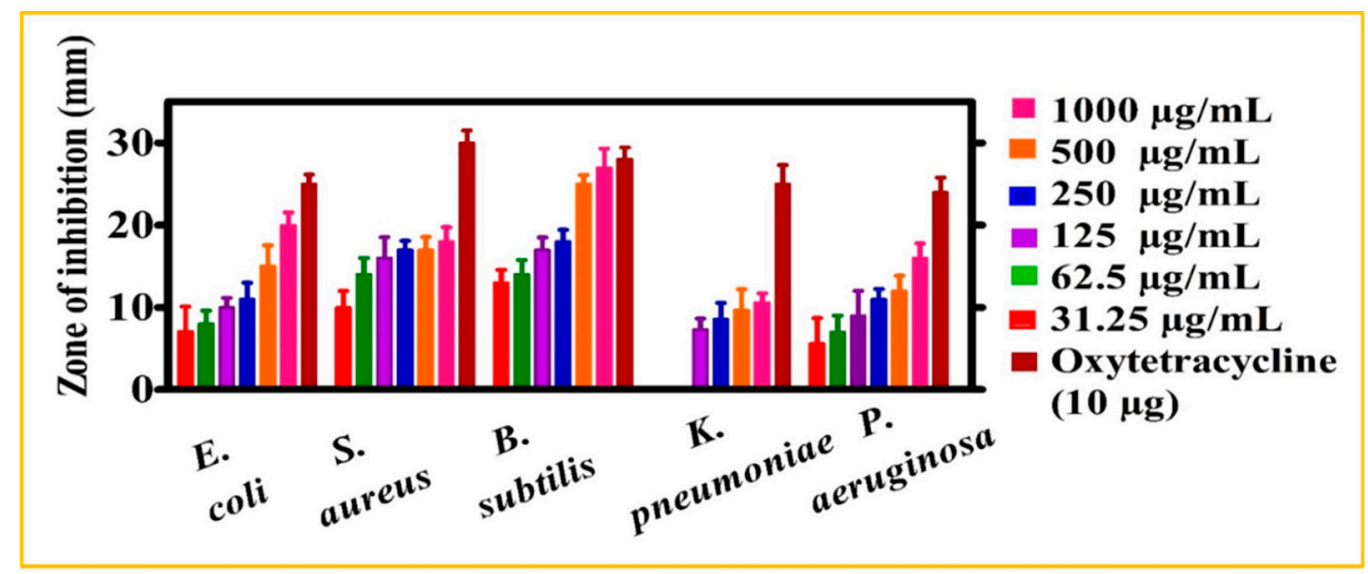

(A)

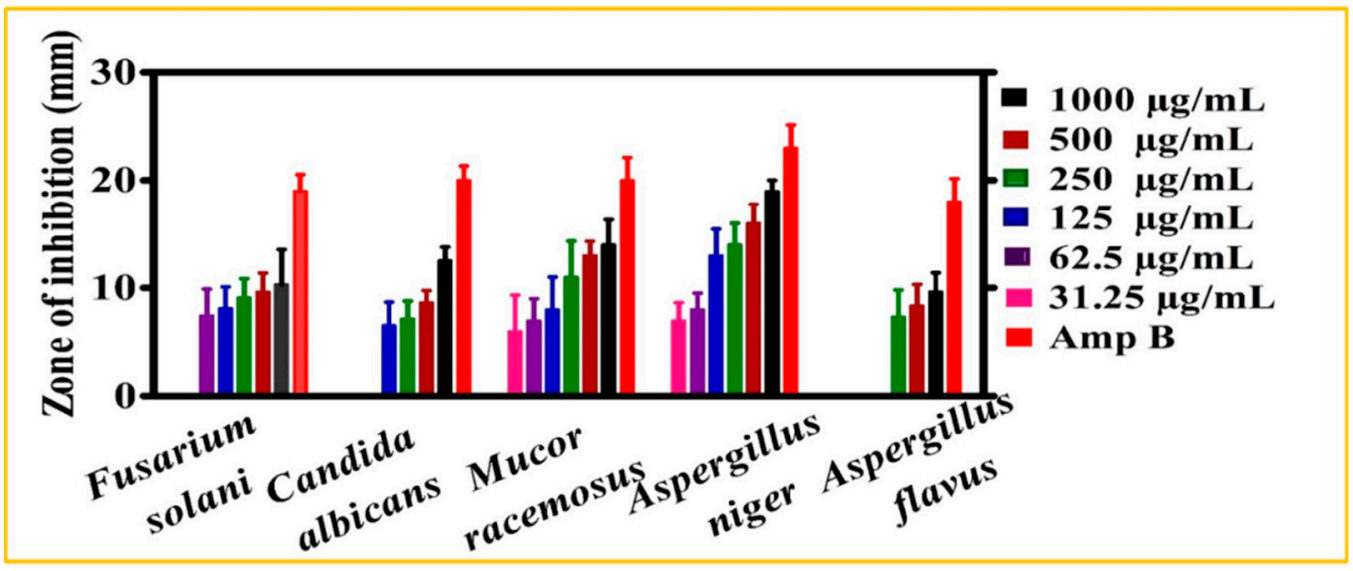

(B)

Figure 7. Antibacterial and antifungal assays. The data in all figures represents the mean of three replicates (A) Antibacterial potential of biogenic ZnONPs (B) Antifungal potential of biogenic ZnONPs.

Furthermore, fungicidal potential of ZnONPs was evaluated using various fungal strains (FS). Before activity was performed different concentration of ZnONPs were prepared ranging from 31.25-1000 $\mu \mathrm{g} / \mathrm{mL}$. The drug amp-B was employed as positive control to compare inhibition potential of ZnONPs. Various FS were used; Fusarium solani, M. racemosus, A. niger, A. flavus and C. albicans (Figure 7B). Substantial work has been performed on antibacterial potentials of ZnONPs while limited fungicidal potentials have been reported for biogenic ZnONPs. Our current study for the first reported 
the fungicidal activity of GW-ZnONPs. For this purpose, different FS were treated with various concentrations of ZnONPs (31.25-1000 $\mu \mathrm{g} / \mathrm{mL})$ to determine their antifungal potentials. Generally, a dose dependent inhibition response was reported for ZnONPs where A. flavus was the least susceptible fungal strain (MIC: $250 \mu \mathrm{g} / \mathrm{mL}$ while A. niger and M. racemosus were the most susceptible strain with MIC: $31.25 \mu \mathrm{g} / \mathrm{mL}$. Among the various FS, M. racemosus, A. niger and F. solani were inhibited at all doses. Besides, ROS, previous studies claim that interaction of ZnONPs with fungal hypea and spores leads to inhibition of their growth. Significant concentration mediated fungicidal assays are reported in previous studies using different fungal strains [34] and are consistent with our present GW-ZnONPs study. MIC values for various bacteria and fungus strain are presented in Table 2.

Table 2. MICs values of different bacterial and fungal strains.

\begin{tabular}{lc}
\hline \multicolumn{2}{c}{ Antibacterial Activity } \\
\hline Bacterial Strain & MIC $(\mu \mathrm{g} / \mathrm{mL})$ \\
\hline Gram Positive \\
\hline S. subtilis (ATCC: 6633$)$ & 7.8 \\
\hline \multicolumn{2}{c}{ Gram Negative } \\
\hline P. aeruginosa (ATCC: 9721$)$ \\
\hline E. coli (ATCC:15224) \\
\hline K. pneumonia (ATCC: 4617) \\
\hline \multicolumn{2}{c}{ Antifungal Activity } \\
\hline Fungal Strain & 15.625 \\
\hline Aspergillus flavus (FCBP: 0064) \\
\hline Aspergillus niger (FCBP: 0918) \\
\hline Candida albicans (FCBP: 478) \\
\hline Fusarium solani (FCBP: 0291) \\
\hline Mucor racemosus (FCBP: 0300) \\
\hline
\end{tabular}

\subsubsection{Enzyme Inhibition Potentials of ZnONPs}

Figure 8A shows protein kinase (PK) enzyme inhibition potential of ZnONPs. These enzymes play significant role in phosphorylation of important amino acids; serine-threonine, tyrosine residues, regulate important processes inside cells like metabolism, apoptosis, proliferations, and differentiation. Deregulated phosphorylation of amino acids can result into genetic abnormalities and result in the development of cancer. Therefore, any substance with potentials to inhibit PK enzymes are of great attention in the field of cancer research [57]. PK phosphorylation has played an important role in the formation of hyphae in Streptomyces fungal strain and same mechanism is used to evaluate the PK inhibition potentials and is utilized to study medicinal compounds for determining PK inhibition [5]. The PK inhibition activity was done via disc diffusion method using different doses of ZnONPs ranging from $31.25-1000 \mu \mathrm{g} / \mathrm{mL}$. The surfactin was taken as a positive control. Different ZOI were observed at different doses of ZnONPs, and the highest ZOI was measured as $15 \mathrm{~mm}$ at $1000 \mu \mathrm{g} / \mathrm{mL}$, which shows important protein kinase inhibition potency of ZnONPs. A concentration-dependent activity is reported for ZnONPs. No single dose has shown stronger potential than the positive control. Therefore, a potential signal transduction inhibitor is identified in the form of nanoscaled $\mathrm{ZnO}$ that can be further exploited for anti-infective and anticancer properties. Because of the protein kinase inhibition property, one can pre-deduce that biosynthesized ZnONPs may play an important role in cancer therapeutics. Our results of PK inhibition are in line with the previous findings [53]. 


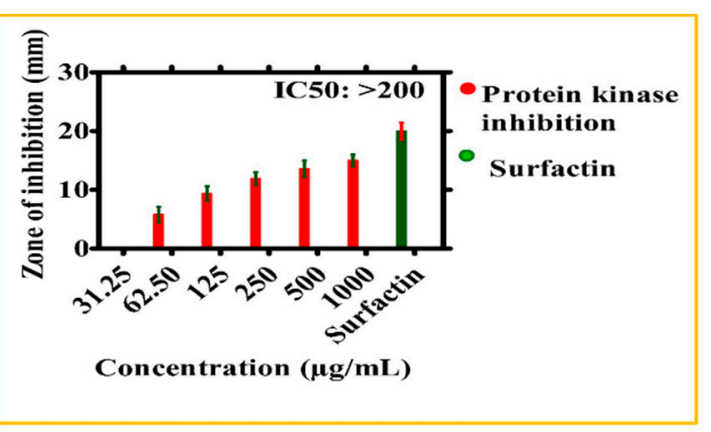

(A)

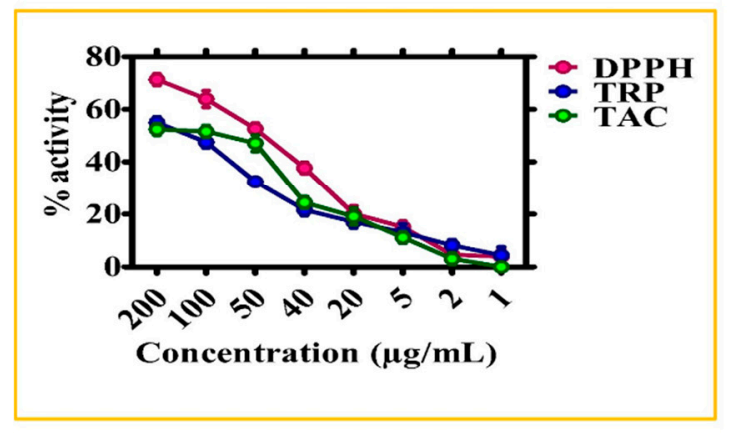

(C)

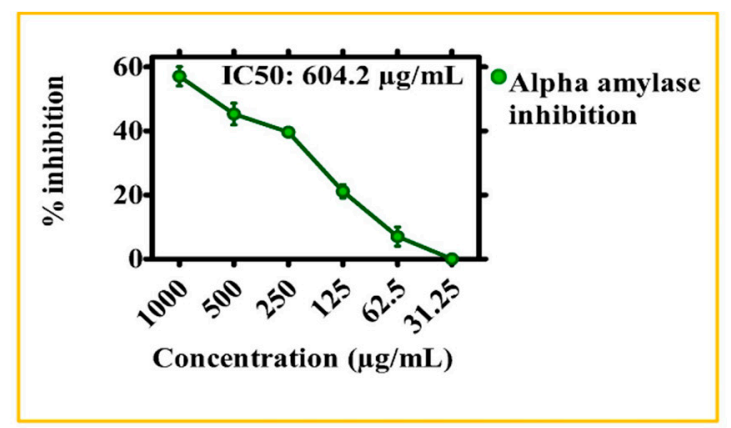

(B)

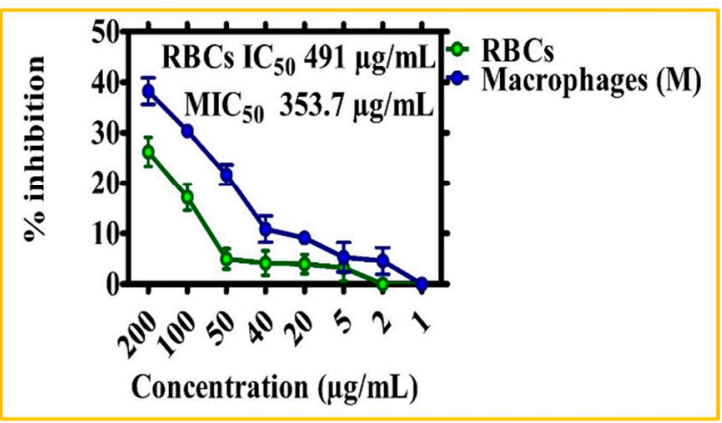

(D)

Figure 8. (A) Inhibition potential of Geranium wallichianum mediated ZnONPs against protein kinase (B) Inhibition potential against alpha amylase (C) Antioxidant potential of ZnONPs (D) Biocompatibility potential of ZnONPs against human RBCs and macrophages.

Besides PK inhibition assay, alpha amylase (AA) inhibition potency of ZnONPs was determined using various concentrations $(31.25-1000 \mu \mathrm{g} / \mathrm{mL}$ ) of ZnONPs. The AA play significant role by converting carbohydrates into glucose [57], therefore, blocking or by inhibiting the activity of alpha amylase can prevent the level of glucose formation; thus, it may provide new insights into a nano level treatment of diabetes [58]. In our study, biogenic ZnONPs were explored for their AA inhibition activity and have determined significant potential by the inhibition of AA. The highest inhibition rate was observed $57 \%$ at $1000 \mu \mathrm{g} / \mathrm{mL}$, while AA inhibition potentials was slowly decreasing with a decrease in concentration of ZnONPs. Figure $8 \mathrm{~B}$ shows the biological inhibition potential of ZnONPs against AA. The results of AA activity are in agreement with the previous findings $[44,53]$.

\subsubsection{Antioxidant Activities of $\mathrm{ZnONPs}$}

Figure $8 \mathrm{C}$ indicates antioxidant potentials of ZnONPs. The antioxidant activities were evaluated in concentration ranging from 1-200 $\mu \mathrm{g} / \mathrm{mL}$. Maximum score for TAC of ZnONPs in terms of AA equivalent/milligrams was reported as $52.43 \%$ at $200 \mu \mathrm{g} / \mathrm{mL}$. TAC assay is mainly used to evaluate the scavenging effect of tested chemicals towards reactive oxygen species (ROS). In the present study, water extract of GW leaves extract was utilized in the reduction and stabilizations of metal ions. It can be concluded from our antioxidant activities, that several phenolic compounds available in the GW leaves extract scavenge ROS which are attached on the surface of ZnONPs.

To further explore the antioxidants species coated on the surface of biogenic nanoparticles, TRP assay was determined. This activity was done to study the reductones that play an important role in the antioxidant potential by providing $\mathrm{H}$-atoms and causing damage to free radical chains [59]. The biosynthesized ZnONPs showed potential antioxidant activity. The reducing power of ZnONPs was decreasing with decrease in concentrations of ZnONPs. The maximum TRP (55\%) was observed at its highest concentration of $200 \mu \mathrm{g} / \mathrm{mL}$. Significant DPPH radicals scavenging activity $(71.36 \%)$ was observed for ZnONPs at $200 \mu \mathrm{g} / \mathrm{mL}$. From data presented in Figure 8C, it can be concluded that 
numerous antioxidants compound may be responsible in reduction and stabilization of ZnONPs via GW leaf extracts. Our antioxidants result of GW-mediated ZnONPs are consistent with the previous studies of ZnONPs via $S$. thea and F. indica $[34,44]$. The variations and disagreement compare to other studies may be due to various important factors like experiment condition, method of nanoparticles fabrication, plant, plant part used, and nanoparticle size, etc.

\subsubsection{Biocompatibility Potential Assays}

The biocompatibility and toxicological effect of zinc oxide nanoparticles were determined using human macrophages and RBCs. Biological substance with hemolytic activity of greater than $5 \%$ are known as hemolytic, between $2-5 \%$ are slightly hemolytic, while less than $2 \%$ is non-hemolytic [60]. If a given nanoparticle is hemolytic, it will rupture red blood cells, which further result in hemoglobin release. To confirm the bio-safe nature, hemolysis assay was conducted using human RBCs. The RBCs were exposed to various concentrations of ZnONPs in a concentration ranging from 200-1 $\mu \mathrm{g} / \mathrm{mL}$. The data obtained have shown that the synthesized are non-hemolytic at lower concentration $(2 \mu \mathrm{g} / \mathrm{mL})$, slightly hemolytic at 5 to $50 \mu \mathrm{g} / \mathrm{mL}$, while hemolytic at concentrations of $>50 \mu \mathrm{g} / \mathrm{mL}$. These results are in agreement to previous reports of $S$. thea mediated ZnONPs [44]. The $\mathrm{IC}_{50}$ value of ZnONPs against human red blood cells was recorded is $491 \mu \mathrm{g} / \mathrm{mL}$. Our research study confirmed that biosynthesized ZnONPs are non-hemolytic and are considered biocompatible in low concentrations.

The biocompatibility assay was further confirmed by using human macrophages. For this purpose, human macrophages were seeded in 96-well plate and were cultured in RPMI media for $24 \mathrm{~h}$ for cells attachment. Further, cells were treated with various concentrations of ZnONPs $(200-1 \mu \mathrm{g} / \mathrm{mL})$. MTT cell viability assay was done to perform biocompatible nature of ZnONPs. The macrophage responded to $\mathrm{ZnONPs}$ treatment in a dose dependent manner. The results indicated that ZnONPs at $200 \mu \mathrm{g} / \mathrm{mL}$ inhibit growth of the macrophages by $\sim 32 \%$ which determine the bio-safe behavior of biogenic ZnONPs. Normally, macrophages have established mechanisms to deal with ROS produce from external source. According to research studies, ROS are non-toxic to both RBCs and macrophages at a lower concentration unless concentration increases beyond that limit which will be considered toxic for RBCs and macrophages [61]. The $\mathrm{IC}_{50}$ value for $\mathrm{ZnONPs}$ was calculated $>353.7 \mu \mathrm{g} / \mathrm{mL}$. The results of biocompatibility assays of ZnONPs are presented in Figure 8D.

\section{Conclusions and Future Perspectives}

In summary, a simple, safe, ecofriendly, and one-step process was used for the biofabrication of ZnONPs utilizing GW leaves extract without utilizing any chemical reagents or surfactants. Different characterization techniques were performed. TEM analysis showed that ZnONPs was of $\sim 18 \mathrm{~nm}$ with a hexagonal shape. Furthermore, different in vitro biological activities of ZnONPs were performed. The bio-potentials of ZnONPs were investigated against different pathogenic microbial strains and confirmed that ZnONPs have shown significant antimicrobial potential. The ZnONPs displayed strong anticancer and antileishmaniasis activities. Furthermore, moderate antioxidant and enzymes inhibition activities have been investigated. The biosafe nature of ZnONPs was confirmed using human RBCs and macrophages. Based on the above findings, we can say that green synthesis is the way forward and new frontier for designing nanomedicine and can be utilized in different theranostic applications for the treatment of different diseases. In addition, different in vivo studies are encouraged on toxicity aspects in different animal models, and once their biocompatibility and bio-safe nature is confirmed, only then can these NPs can be utilized in clinical applications. Further studies are encouraged on the mechanistic and synthesis aspects of the ZnONPs by using different medicinal plant materials.

Author Contributions: Conceptualization, B.A.A., J.I., R.A., L.Z., S.K., C.W., T.M., and J.-T.C.; writing-original draft preparation, B.A.A., J.I., and R.A.; writing-review and editing, L.Z., S.K., C.W., T.M., and J.-T.C. All authors have read and agreed to the published version of the manuscript.

Funding: This research received no external funding. 
Conflicts of Interest: The authors declare no conflict of interest.

\section{References}

1. Munir, A.; Haq, T.U.; Hussain, I.; Qurashi, A.; Ullah, U.; Iqbal, M.J.; Hussain, I. Ultrasmall Co@Co(OH $)_{2}$ Nanoclusters Embedded in N-Enriched Mesoporous Carbon Network as Efficient Electrocatalysts for Durable Water Oxidation. ChemSusChem 2019, 12, 5117-5125. [CrossRef]

2. Mayedwa, N.; Mongwaketsi, N.; Khamlich, S.; Kaviyarasu, K.; Matinise, N.; Maaza, M. Green synthesis of nickel oxide, palladium and palladium oxide synthesized via Aspalathus linearis natural extracts: Physical properties \& mechanism of formation. Appl. Surf. Sci. 2018, 446, 266-272.

3. Yoon, W.J.; Jung, K.Y.; Liu, J.; Duraisamy, T.; Revur, R.; Teixeira, F.L.; Berger, P.R. Lasmon-enhanced optical absorption and photocurrent in organic bulk heterojunction photovoltaic devices using self-assembled layer of silver nanoparticles. Sol. Energy Mater. Sol. Cells 2010, 94, 128-132. [CrossRef]

4. Iqbal, J.; Abbasi, B.A.; Ahmad, R.; Mahmood, T.; Ali, B.; Khalil, A.T.; Kanwal, S.; Shah, S.A.; Alam, M.M.; Badshah, H.; et al. Nanomedicines for developing cancer nanotherapeutics: From benchtop to bedside and beyond. Appl. Microbiol. Biotechnol. 2018, 102, 9449-9470. [CrossRef] [PubMed]

5. Abbasi, B.A.; Iqbal, J.; Mahmood, T.; Ahmad, R.; Kanwal, S.; Afridi, S. Plant-mediated synthesis of nickel oxide nanoparticles $(\mathrm{NiO})$ via Geranium wallichianum: Characterization and different biological applications. Mater. Res. Exp. 2019, 6, 0850a7. [CrossRef]

6. Thema, F.T.; Manikandan, E.; Dhlamini, M.S.; Maaza, M. Green synthesis of ZnO nanoparticles via Agathosma betulina natural extract. Mater. Lett. 2015, 15, 124-127. [CrossRef]

7. Kalusniak, S.; Sadofev, S.; Puls, J.; Henneberger, F. ZnCdO/ZnO-A new heterosystem for green-wavelength semiconductor lasing. Laser Photonics Rev. 2009, 3, 233-242. [CrossRef]

8. Yang, Y.; Jin, P.; Zhang, X.; Ravichandran, N.; Ying, H.; Yu, C.; Wu, M. New epigallocatechin gallate (EGCG) nanocomplexes co-assembled with 3-mercapto-1-hexanol and $\beta$-lactoglobulin for improvement of antitumor activity. J. Biomed. Nanotechnol. 2017, 13, 805-814. [CrossRef]

9. Mirzaei, H.; Darroudi, M. Zinc oxide nanoparticles: Biological synthesis and biomedical applications. Ceram. Int. 2017, 43, 907-914. [CrossRef]

10. Kawakami, M.; Hartanto, A.B.; Nakata, Y.; Okada, T. Synthesis of ZnO nanorods by nanoparticle assisted pulsed-laser deposition. Jpn. J. Appl. Phys. 2003, 42, 1-33. [CrossRef]

11. Liu, X.; Wu, X.; Cao, H.; Chang, R.P. Growth mechanism and properties of ZnO nanorods synthesized by plasma-enhanced chemical vapor deposition. J. Appl. Phys. 2004, 95, 3141-3147. [CrossRef]

12. Zhang, X.H.; Liu, Y.C.; Wang, X.H.; Chen, S.J.; Wang, G.R.; Zhang, J.Y.; Fan, X.W. Structural properties and photoluminescence of $\mathrm{ZnO}$ nanowalls prepared by two-step growth with oxygen-plasma-assisted molecular beam epitaxy. J. Phys. Condens. Matter 2005, 17, 3035. [CrossRef]

13. Gondal, M.A.; Drmosh, Q.A.; Yamani, Z.H.; Saleh, T.A. Synthesis of ZnO2 nanoparticles by laser ablation in liquid and their annealing transformation into ZnO nanoparticles. Appl. Surf. Sci. 2009, 256, $298-304$. [CrossRef]

14. Guzmán, M.G.; Dille, J.; Godet, S. Synthesis of silver nanoparticles by chemical reduction method and their antibacterial activity. Int. J. Chem. Biomol. Eng. 2009, 2, 104-111.

15. Tahir, M.N.; Natalio, F.; Cambaz, M.A.; Panthöfer, M.; Branscheid, R.; Kolb, U.; Tremel, W. Controlled synthesis of linear and branched Au@ ZnO hybrid nanocrystals and their photocatalytic properties. Nanoscale 2013, 5, 9944-9949. [CrossRef]

16. Polavarapu, L.; Liz-Marzán, L.M. Growth and galvanic replacement of silver nanocubes in organic media. Nanoscale 2013, 5, 4355-4361. [CrossRef]

17. Yadav, R.S.; Mishra, P.; Pandey, A.C. Growth mechanism and optical property of ZnO nanoparticles synthesized by sonochemical method. Ultrason. Sonochem. 2008, 15, 863. [CrossRef]

18. Barhoum, A.; Van Assche, G.; Rahier, H.; Fleisch, M.; Bals, S.; Delplancked, M.P.; Bahnemann, D. Sol-gel hot injection synthesis of $\mathrm{ZnO}$ nanoparticles into a porous silica matrix and reaction mechanism. Mater. Des. 2017, 119, 270-276. [CrossRef]

19. Iravani, S.; Korbekandi, H.; Mirmohammadi, S.V.; Zolfaghari, B. Synthesis of silver nanoparticles: Chemical, physical and biological methods. Res. Pharm. Sci. 2014, 9, 385. 
20. Duran, N.; Seabra, A.B. Biogenic synthesized Ag/Au nanoparticles: Production, characterization, and applications. Curr. Nanosci. 2018, 14, 82-94. [CrossRef]

21. Seabra, A.B.; Duran, N. Nanotoxicology of metal oxide nanoparticles. Metals 2015, 5, 934-975. [CrossRef]

22. Singh, P.; Kim, Y.J.; Zhang, D.; Yang, D.C. Biological synthesis of nanoparticles from plants and microorganisms. Trends. Biotechnol. 2016, 34, 588-599. [CrossRef] [PubMed]

23. Durán, N.; Marcato, P.D.; Durán, M.; Yadav, A.; Gade, A.; Rai, M. Mechanistic aspects in the biogenic synthesis of extracellular metal nanoparticles by peptides, bacteria, fungi, and plants. Appl. Microbiol. Biotechnol. 2011, 90, 1609-1624. [CrossRef] [PubMed]

24. KS, S.; Vellora Thekkae Padil, V.; Senan, C.; Pilankatta, R.; George, B.; Wacławek, S.; Černík, M. (Green Synthesis of High Temperature Stable Anatase Titanium Dioxide Nanoparticles Using Gum Kondagogu: Characterization and Solar Driven Photocatalytic Degradation of Organic Dye. Nanomaterials 2018, 8, 1002.

25. Iqbal, J.; Abbasi, B.A.; Batool, R.; Khalil, A.T.; Hameed, S.; Kanwal, S.; Mahmood, T. Biogenic synthesis of green and cost effective cobalt oxide nanoparticles using Geranium wallichianum leaves extract and evaluation of in vitro antioxidant, antimicrobial, cytotoxic and enzyme inhibition properties. Mater. Res. Express 2019, 6, 115407. [CrossRef]

26. Hameed, S.; Shah, S.A.; Iqbal, J.; Numan, M.; Muhammad, W.; Junaid, M.; Umer, F. Cannabis sativa Mediated Synthesis of Gold Nanoparticles and its Biomedical Properties. Bioinspired Biomim. Nanobiomater. 2019, 1-8. [CrossRef]

27. Mohamed, H.E.A.; Afridi, S.; Khalil, A.T.; Zia, D.; Iqbal, J.; Ullah, I.; Maaza, M. Biosynthesis of silver nanoparticles from Hyphaene thebaica fruits and their in vitro pharmacognostic potential. Mater. Res. Express 2019, 6, 1050c9. [CrossRef]

28. Abbasi, B.A.; Iqbal, J.; Mahmood, T.; Qyyum, A.; Kanwal, S. Biofabrication of iron oxide nanoparticles by leaf extract of Rhamnus virgata: Characterization and evaluation of cytotoxic, antimicrobial and antioxidant potentials. Appl. Organomet. Chem. 2019, 33, e4947. [CrossRef]

29. Iqbal, J.; Abbasi, B.A.; Ahmad, R.; Mahmood, T.; Kanwal, S.; Ali, B.; Badshah, H. Ursolic acid a promising candidate in the therapeutics of breast cancer: Current status and future implications. Biomed. Pharmacother. 2018, 108, 752-756. [CrossRef]

30. Abbasi, B.A.; Iqbal, J.; Mahmood, T.; Khalil, A.T.; Ali, B.; Kanwal, S.; Ahmad, R. Role of dietary phytochemicals in modulation of miRNA expression: Natural swords combating breast cancer. Asian. Pac. J. Trop. Med. 2018, 11, 501-509.

31. Bhuyan, T.; Mishra, K.; Khanuja, M.; Prasad, R.; Varma, A. Biosynthesis of zinc oxide nanoparticles from Azadirachta indica for antibacterial and photocatalytic applications. Mater. Sci. Semicond. Process. 2015, 32, 55-61. [CrossRef]

32. Hameed, S.; Iqbal, J.; Ali, M.; Khalil, A.T.; Abbasi, B.A.; Numan, M.; Shinwari, Z.K. Green synthesis of zinc nanoparticles through plant extracts: Establishing a novel era in cancer theranostics. Mater. Res. Express 2019, 6, 102005. [CrossRef]

33. Matinise, N.; Fuku, X.G.; Kaviyarasu, K.; Mayedwa, N.; Maaza, M. ZnO nanoparticles via Moringa oleifera green synthesis: Physical properties \& mechanism of formation. Appl. Surf. Sci. 2017, 406, 339-347.

34. Ismail, M.; Ibrar, M.; Iqbal, Z.; Hussain, J.; Hussain, H.; Ahmed, M.; Choudhary, M.I. Chemical constituents and antioxidant activity of Geranium wallichianum. Records. Natl. Prod. 2009, 3, 193-197.

35. Ellis, S.; Taylor, D.M.; Masood, K.R. Soil formation and erosion in the Murree Hills, northeast Pakistan. Catena 1994, 22, 69-78. [CrossRef]

36. Iqbal, J.; Abbasi, B.A.; Mahmood, T.; Hameed, S.; Munir, A.; Kanwal, S. Green synthesis and characterizations of Nickel oxide nanoparticles using leaf extract of Rhamnus virgata and their potential biological applications. Appl. Organometal. Chem. 2019, e4950. [CrossRef]

37. Fatima, H.; Khan, K.; Zia, M.; Ur-Rehman, T.; Mirza, B.; Haq, I.U. Extraction optimization of medicinally important metabolites from Datura innoxia Mill.: An in vitro biological and phytochemical investigation. BMC Complement. Altern. Med. 2015, 15, 376-394. [CrossRef]

38. Satpathy, S.; Patra, A.; Ahirwar, B.; Delwar Hussain, M. Antioxidant and anticancer activities of green synthesized silver nanoparticles using aqueous extract of tubers of Pueraria tuberosa. Artif. Cells Nanomed. Biotechnol. 2018, 46, 71-85. [CrossRef] 
39. Baqi, A.; Tareen, R.B.; Mengal, A.; Khan, N.; Behlil, F.; Achakzai, A.K.K.; Faheem, M. Determination of antioxidants in two medicinally important plants, Haloxylon griffithii and Convolvulus leiocalycinus of Balochistan. Pure Appl. Biol. 2018, 7, 296-308. [CrossRef]

40. De Almeida, M.C.; Silva, A.C.; Barral, A.; Barral Netto, M. A simple method for human peripheral blood monocyte isolation. Memorias do Instituto Oswaldo Cruz 2000, 95, 221-223. [CrossRef]

41. Malagoli, D. A full-length protocol to test hemolytic activity of palytoxin on human erythrocytes. Invertebrate. Surviv. J. 2007, 4, 92-94.

42. Ibrahim, H.M. Green synthesis and characterization of silver nanoparticles using banana peel extract and their antimicrobial activity against representative microorganisms. J. Radic. Res. Appl. Sci. 2015, 8, 265. [CrossRef]

43. Zak, A.K.; Razali, R.; Majid, W.A.; Darroudi, M. Synthesis and characterization of a narrow size distribution of zinc oxide nanoparticles. Int. J. Nanomed. 2011, 6, 1399-1403.

44. Khalil, A.T.; Ovais, M.; Ullah, I.; Ali, M.; Shinwari, Z.K.; Hassan, D.; Maaza, M. Sageretia thea (Osbeck.) modulated biosynthesis of $\mathrm{NiO}$ nanoparticles and their in vitro pharmacognostic, antioxidant and cytotoxic potential. Artif. Cells Nanomed. Biotechnol. 2018, 46, 838-852. [CrossRef]

45. Suresh, J.; Pradheesh, G.; Alexramani, V.; Sundrarajan, M.; Hong, S.I. Green synthesis and characterization of zinc oxide nanoparticle using insulin plant (Costus pictus D. Don) and investigation of its antimicrobial as well as anticancer activities. Adv. Nat. Sci. Nanosci. Nanotechnol. 2018, 9, 015008. [CrossRef]

46. Tahir, K.; Nazir, S.; Ahmad, A.; Li, B.; Khan, A.U.; Khan, Z.U.H.; Rahman, A.U. Facile and green synthesis of phytochemicals capped platinum nanoparticles and in vitro their superior antibacterial activity. J. Photochem. Photobiol. B Biol. 2017, 166, 246. [CrossRef]

47. Khan, F.U.; Chen, Y.; Khan, N.U.; Ahmad, A.; Tahir, K.; Khan, Z.U.; Wan, P. Visible light inactivation of E. coli, Cytotoxicity and ROS determination of biochemically capped gold nanoparticles. Microb. Pathog. 2017, 107, 419-424. [CrossRef]

48. Yedurkar, S.; Maurya, C.; Mahanwar, P. Biosynthesis of zinc oxide nanoparticles using ixora coccinea leaf extract-A green approach. Open J. Synth. Theory Appl. 2016, 5, 1-14. [CrossRef]

49. Iqbal, J.; Abbasi, B.A.; Ahmad, R.; Batool, R.; Mahmood, T.; Ali, B.; Bashir, S. Potential phytochemicals in the fight against skin cancer: Current landscape and future perspectives. Biomed. Pharmacother. 2019, 109, 1381-1393. [CrossRef]

50. Iqbal, J.; Abbasi, B.A.; Batool, R.; Mahmood, T.; Ali, B.; Khalil, A.T.; Ahmad, R. Potential phytocompounds for developing breast cancer therapeutics: nature's healing touch. Eur. J. Pharmacol. 2018, 827, 125-148. [CrossRef]

51. Daher, S.; Massarwa, M.; Benson, A.A.; Khoury, T. Current and future treatment of hepatocellular carcinoma: An updated comprehensive review. J. Clin. Trans. Hepatol. 2018, 6, 69-78. [CrossRef] [PubMed]

52. Hassan, H.F.H.; Mansour, A.M.; Abo-Youssef, A.M.H.; Elsadek, B.E.; Messiha, B.A.S. Zinc oxide nanoparticles as a novel anticancer approach; in vitro and in vivo evidence. Clin. Exp. Pharmacol. Physiol. 2017, 44, 235-243. [CrossRef] [PubMed]

53. Iqbal, J.; Abbasi, B.A.; Mahmood, T.; Kanwal, S.; Ahmad, R.; Ashraf, M. Plant-extract mediated green approach for the synthesis of ZnONPs: Characterization and evaluation of cytotoxic, antimicrobial and antioxidant potentials. J. Mol. Struct. 2019, 1189, 315-327. [CrossRef]

54. Kaye, P.; Scott, P. Leishmaniasis: Complexity at the host-pathogen interface. Nat. Rev. Microbiol. 2011, 9, 604-611. [CrossRef] [PubMed]

55. Safawo, T.; Sandeep, B.V.; Pola, S.; Tadesse, A. Synthesis and characterization of zinc oxide nanoparticles using tuber extract of anchote (Coccinia abyssinica (Lam.) Cong.) for antimicrobial and antioxidant activity assessment. Open Nano 2018, 3, 56-63. [CrossRef]

56. Li, Y.; Zhang, W.; Niu, J.; Chen, Y. Mechanism of photogenerated reactive oxygen species and correlation with the antibacterial properties of engineered metal-oxide nanoparticles. ACS Nano 2012, 6, 5164-5173. [CrossRef]

57. Yao, G.; Sebisubi, F.M.; Voo, L.Y.C.; Ho, C.C.; Tan, G.T.; Chang, L.C. Citrinin derivatives from the soil filamentous fungus Penicillium sp. H9318. J. Braz. Chem. Soc. 2011, 22, 1125-1129. [CrossRef]

58. Oyedemi, S.O.; Oyedemi, B.O.; Ijeh, I.I.; Ohanyerem, P.E.; Coopoosamy, R.M.; Aiyegoro, O.A. Alpha-amylase inhibition and antioxidative capacity of some antidiabetic plants used by the traditional healers in Southeastern Nigeria. Sci. World J. 2017, 2017, 3592491. [CrossRef] 
59. Ul-Haq, I.; Ullah, N.; Bibi, G.; Kanwal, S.; Ahmad, M.S.; Mirza, B. Antioxidant and cytotoxic activities and phytochemical analysis of Euphorbia wallichii root extract and its fractions. Iran. J. Pharm. Res. 2012, 11, 241-249.

60. Dobrovolskaia, M.A.; Clogston, J.D.; Neun, B.W.; Hall, J.B.; Patri, A.K.; McNeil, S.E. Method for analysis of nanoparticle hemolytic properties in vitro. Nano Lett. 2008, 8, 2180-2187. [CrossRef]

61. Prach, M.; Stone, V.; Proudfoot, L. Zinc oxide nanoparticles and monocytes: Impact of size, charge and solubility on activation status. Toxicol. Appl. Pharmacol. 2013, 266, 19-26. [CrossRef] [PubMed]

(C) 2019 by the authors. Licensee MDPI, Basel, Switzerland. This article is an open access article distributed under the terms and conditions of the Creative Commons Attribution (CC BY) license (http://creativecommons.org/licenses/by/4.0/). 